\title{
8
}
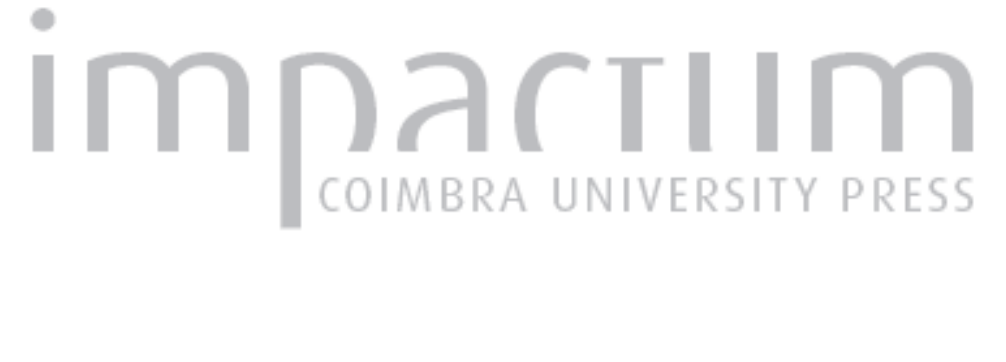

\section{Método de análise de risco de incêndios em Favelas: uma abordagem}

Autor(es): Bruno, Ana Paula

Publicado por: Associação Portuguesa de Riscos, Prevenção e Segurança

URL persistente:

URI:http://hdl.handle.net/10316.2/36101

DOI:

DOI:http://dx.doi.org/10.14195/1647-7723_17_12

Accessed : $\quad$ 26-Apr-2023 12:41:21

A navegação consulta e descarregamento dos títulos inseridos nas Bibliotecas Digitais UC Digitalis, UC Pombalina e UC Impactum, pressupõem a aceitação plena e sem reservas dos Termos e Condições de Uso destas Bibliotecas Digitais, disponíveis em https://digitalis.uc.pt/pt-pt/termos.

Conforme exposto nos referidos Termos e Condições de Uso, o descarregamento de títulos de acesso restrito requer uma licença válida de autorização devendo o utilizador aceder ao(s) documento(s) a partir de um endereço de IP da instituição detentora da supramencionada licença.

Ao utilizador é apenas permitido o descarregamento para uso pessoal, pelo que o emprego do(s) título(s) descarregado(s) para outro fim, designadamente comercial, carece de autorização do respetivo autor ou editor da obra.

Na medida em que todas as obras da UC Digitalis se encontram protegidas pelo Código do Direito de Autor e Direitos Conexos e demais legislação aplicável, toda a cópia, parcial ou total, deste documento, nos casos em que é legalmente admitida, deverá conter ou fazer-se acompanhar por este aviso.

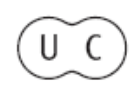




\section{territorium}

Riscos, Sociedade(s) e Segurança

Revista da Associação Portuguesa de Riscos, Prevenção e Segurança 2010 
territorium 17, 2010, 119-126

journal homepage: http://www.nicif.pt/riscos/Territorium/numeros_publicados

MÉTODO DE ANÁLISE DE RISCO DE INCÊNDIOS EM FAVELAS: UMA ABORDAGEM ${ }^{\text {* }}$

Ana Paula Bruno

Doutoranda no Programa de Pós-Graduação da Faculdade de Arquitetura e Urbanismo da Universidade de São Paulo - FAUUSP apbruno@yahoo.com.br

\section{RESUMO}

A partir da apresentação das favelas no contexto da habitação popular urbana no Brasil e, em especial, na cidade de São Paulo, o problema dos incêndios é brevemente construído, para então ser explorada a gestão do risco associado a esse tipo de evento, por meio da proposição de um método de análise alinhado aos objetivos, possibilidades e limitações concretas à sua aplicação.

Palavras chave: risco, incêndio, favela, gestão, metodologia.

\section{RÉSUMÉ}

Méthode d'analyse du risque d'incendie dans les bidonvilles: une approche. En déboutant de la présentation des bidonvilles dans le contexte d'habitations populaires, et en particulier à São Paulo, le problème des incendies est brièvement décrit, pour explorer ensuite la gestion du risque associé à ce type d'occurrence, par l'indication d'une méthode d'analyse en consonnance avec les objectifs, possibilités et limitations concrètes pour son application.

Mots-clé: risque, incendie, bidonvilles, gestion, méthodologie.

\section{ABSTRACT}

Method of risk analysis of fire in slums: an approach. From the exposition of slums on the context of the urban social housing in Brasil and, specially, in the city of São Paulo, the problem of fire is briefly constructed. Then, the risk management related to this kind of event is exploited, through the proposition of an analysis method aligned to the objectives, the concrete possibilities and limitations for its application.

Key words: risk, fire, slum, management, methodology

$1^{*} \mathrm{O}$ texto deste artigo corresponde à comunicação apresentada ao V Encontro Nacional e I Congresso Internacional de Riscos e foi submetido para revisão em 19-06-2009, tendo sido aceite para publicação em 31-03-2010.

Este artigo é parte integrante da Revista Territorium, n. ${ }^{\circ} 17,2010$, $\odot$ Riscos, ISBN: 0872- 8941 


\section{Introdução}

0 processo de urbanização brasileiro, intensificado na metade do Século XX, conheceu seu apogeu a partir da década de 1970, data em que a população urbana superou a rural, alcançando cerca de 53 milhões de habitantes ou $56 \%$ da população total do país (ReIs FiLHo, 1996, p.12). Paralelamente, começava a se instalar na cidade de São Paulo uma nova alternativa de moradia para a população de baixa renda, as favelas, que até à década de 1970 se expressavam apenas timidamente na capital paulista ${ }^{1}$.

Desde então, o crescimento da população favelada paulistana passou a ser sempre superior ao incremento populacional da cidade como um todo². O primeiro cadastro de favelas do Município de São Paulo, realizado pela Prefeitura em 1973, contabilizou 14.500 domicílios e estimou a sua população em 71.840 pessoas, o que representava $1,1 \%$ do total da cidade. Sete anos depois, em 1980, esse índice atingiu 5\% (TASCHNER, 1997, p.30); mais sete anos e um novo censo de favelas (1987), também realizado pela Prefeitura "encontrou o total de 812.764 moradores em favela no município, 8,9\% da população municipal, em mais de 150 mil domicílios" (TASCHNER, 2001, p.2).

Estimativas oficiais mais recentes demonstram que, embora num ritmo inferior às décadas iniciais, as favelas continuaram a crescer: em 1991, chegou-se a 891.673 pessoas, num total de 196.389 domicílios; em 2001, 1.160.590 pessoas, em 286.954 domicílios (TORRES et. al, 2003, p.22); e, na última atualização, em 2008, 1.539.271 pessoas, em 377.236 domicílios (SEADE, 2008, p.6), representando, respectivamente, 9,1\%, 11,1\% e $14,2 \%$ da população total do Município (QUADRO I).

QuAdRo I - População residente em favelas no Município de São Paulo (\%).

\begin{tabular}{|l|c|c|c|c|c|c|}
\hline & 1973 & 1980 & 1987 & 1991 & 2001 & 2008 \\
\hline População residente em favelas (\%) & 1,1 & 5 & 8,9 & 9,1 & 11,1 & 14,2 \\
\hline
\end{tabular}

Assim, a alternativa favela - resultado da associação entre um modelo de "industrialização com baixos salários", em que "o custo da reprodução da força de trabalho não inclui o custo da mercadoria habitação" (MARICATO, 2000, p.155), uma dificuldade cada vez maior de acesso à terra urbana, determinada, além da escassez, por medidas legais que desestimularam e encareceram a produção de lotes populares, e, nesse entremeio, da ausência de uma política oficial de habitação consistente - tornou-se protagonista no cenário urbano paulistano.

Por outro lado, foi também num processo que a resposta oficial para o problema da habitação popular urbana, em grande medida por pressão de movimentos sociais organizados em torno da questão da moradia, passou, nesse viés, da erradicação (desde a sua instalação) à promoção de melhorias básicas (a partir de meados dos anos 1970), até chegar atualmente (nos últimos dez a vinte anos, a depender de qual cidade brasileira se está a falar), à consolidação dos assentamentos informais (incluído favelas e loteamentos irregulares) na cidade, por meio de ações cada vez mais coordenadas de urbanização e regularização jurídica, no que se chama hoje de regularização fundiária plena ${ }^{3}$.

Esse contexto, de generalização da favela como alternativa habitacional e de sua consolidação no espaço urbano, coloca algumas questões para a formulação e a gestão de políticas públicas ligadas ao problema. A principal delas - que permeia todas as outras e já vem determinando o desenho da atuação institucional - é a escala.

Considerando as dimensões assumidas nos últimos trinta anos e a conseqüente dificuldade em universalizar, em curto ou médio prazo, soluções integrais para as deficiências inerentes a esse tipo de ocupação, em seus diversos aspectos, o Poder Público tem, no seu poderdever de agir, atuado no tratamento de situações críticas, que acarretem risco à vida da população envolvida, por meio da adoção de medidas preventivas e emergenciais.

Exemplo disso são os programas de gerenciamento de riscos geotécnicos associados a ocupações inadequadas de encostas e fundos de vale, para as quais já existem parâmetros metodológicos consistentes, consagrados por uma ampla gama de experiências práticas e estudos acadêmicos correlatos ${ }^{4}$. No caso dos incêndios, entretanto, isso não acontece.

\section{Incêndios em favelas: um novo problema?}

O pouco acúmulo de conhecimento acerca dos incêndios em favelas ${ }^{5}$, bem como o (não) tratamento correntemente a eles dispensado pelo Poder Público no Brasil - com exceção, evidentemente, dos corpos de bombeiros - nos faz pensar se este é um problema novo. Seriam os incêndios em favelas fenômenos recentes, das últimas décadas, ou estes as teriam acompanhado desde o seu surgimento? Objetivamente, esta não é uma questão fácil de responder: tanto os dados de incêndios quanto os dados de favelas, numa perspectiva histórica, não possuem consistência suficiente para tornar possível traçar uma evolução precisa dos eventos e de sua severidade ${ }^{6}$.

Entretanto, dados referentes ao período compreendido entre os anos de 1993 e 2003, circunscritos à cidade de São Paulo, nos mostram que a ocorrência desse tipo de evento é bastante significativa: registraram-se em média 194 incêndios em barracos ao ano, ou cerca de um a cada 
dois dias, e 48 incêndios em favelas, ou cerca de um por semana, sendo que de 2001 a 2003, quando ocorreram 593 eventos ao total, foram feitas trinta e duas vítimas feridas e quatorze fatais $^{7}$.

A interpretação dos dados também aponta um incremento importante na propagação do fogo em favelas ${ }^{8}$, possivelmente relacionado com o adensamento das ocupações, observado dos anos 1990 em diante (fig. 1).

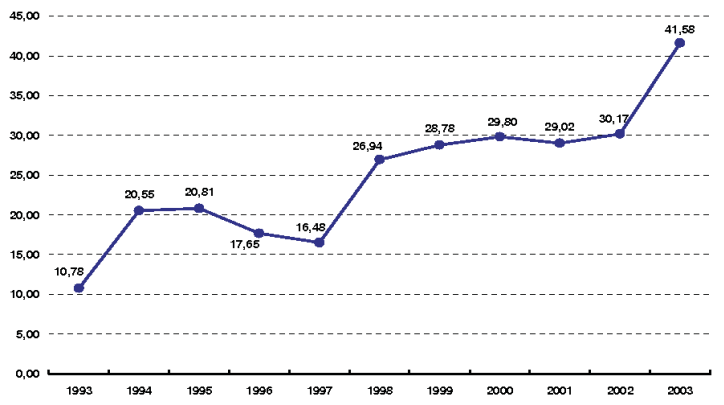

Fig. 1 - Percentual de focos de fogo em favelas que se transformaram em incêndios.

Não obstante isso, a questão determinante para a construção dos incêndios em favelas como problema necessária também à construção de uma atuação sobre eles - reside na noção de que esse tipo de assentamento não é provisório, e, principalmente, na desmistificação da idéia de que esse tipo de incêndio é estritamente imprevisível, ou, de maneira subjacente, não é gerenciável. Ora, se o caminho assumido no campo da política habitacional implica na consolidação das favelas, deve-se partir, então, da premissa de que esse modo de viver possa ser exercido em condições satisfatórias de segurança.

A regularização fundiária plena, quando afirma o objetivo da integração dos assentamentos irregulares no contexto da cidade formal, em outras palavras quer dizer, para além da realização de obras de infra-estrutura e regularização jurídica da posse da terra, a promoção, com as devidas adaptações, de um nivelamento substantivo dos bens e serviços públicos disponíveis aos diversos territórios da cidade. Dentre estes, a cobertura por um sistema de segurança contra incêndios, em todos os seus aspectos.

\section{Fatores de risco de incêndios em favelas}

Basicamente, os elementos essenciais para que um incêndio se inicie e se desenvolva são a presença de fontes de calor e de material combustível, dado que o comburente seja o ar. As suas disponibilidade e interação no ambiente, bem como as características deste próprio ambiente, determinam a severidade do evento e as perdas dele decorrentes, que podem ser humanas, materiais ou ambas, de maior ou menor extensão.

Assim, são objetivos da segurança contra incêndios reduzir as probabilidades da ocorrência de eventos e, no caso destes se configurarem, reduzir seus impactos, sobretudo sobre vidas humanas. Para tanto, há um extenso conjunto de medidas tradicionalmente adotadas em edificações, que perpassa as fases, sistematizadas por Rosso (1975), da prevenção, confinamento, combate e rescaldo, visando:

- a conscientização e esclarecimento, de modo a provocar na população atitudes comprometidas com prevenção de incêndios, uma vez que grande parte deles, como poderemos ver adiante no estudo de suas causas, é ocasionada por negligência, desconhecimento ou imperícia na manipulação de fontes de calor;

- o controle das fontes de calor e de materiais de fácil combustão e de sua interação, por meio de seu apartamento (chamas e tecidos, por exemplo), da segregação de áreas da edificação em que haja acondicionamento de materiais inflamáveis (áreas de serviço, abrigos de botijões de gás) e ambientes em que sejam operadas fontes abertas de calor, (cozinhas), da especificação das características, quanto à combustão e toxidade, quantidade e distribuição dos materiais e componentes nos ambientes, do bom dimensionamento, execução e manutenção de projeto e obra, de acordo com as regulamentações vigentes, especialmente no que se refere às instalações elétricas;

- a ágil detecção e o controle do foco inicial, por meio da instalação de detectores de fogo e de fumaça, de avisos (alarmes visuais ou sonoros), de equipamentos de combate imediato, que podem ser automáticos, como sprinklers, ou manuais, como extintores, hidrantes, mangueiras, neste caso operados por pessoal devidamente treinado (brigadas de incêndio), da agilidade na comunicação da ocorrência aos corpos de bombeiros e da correção das informações prestadas quando do aviso;

- o gerenciamento do incêndio e do exposto (pessoas e bens), por meio da previsão de disponibilidade de água em volume e pressão suficientes para a ação de combate, de condições de acesso ao local do sinistro, que devem ser compatíveis com a estrutura dos veículos e equipamentos dos corpos de bombeiros, do controle do pânico generalizado e da evacuação do imóvel (orientação pelos brigadistas do fluxo de pessoas até local seguro), da clareza/ facilidade de compreensão das rotas, percursos e áreas de refúgio para salvamento das vítimas, relacionadas com soluções de projeto que levem em conta esses fatores. 
Sob esse ponto de vista, quando analisamos as favelas, é fácil observar que não só elas desobedecem a essa lógica estruturada, como possuem características que a contrariam. São elas 9 :

- configuração urbanística dos assentamentos, com impactos no alastramento do fogo, no combate

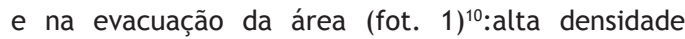
populacional, de cerca de 560 pessoas/ ha; alta densidade domiciliar, de cerca de 140 domicílios/ ha; alta densidade construtiva: $46,9 \%$ dos domicílios possui mais de um pavimento; precariedade do sistema viário: $35,1 \%$ dos domicílios não são servidos por coleta de lixo na porta, o que indica a impossibilidade

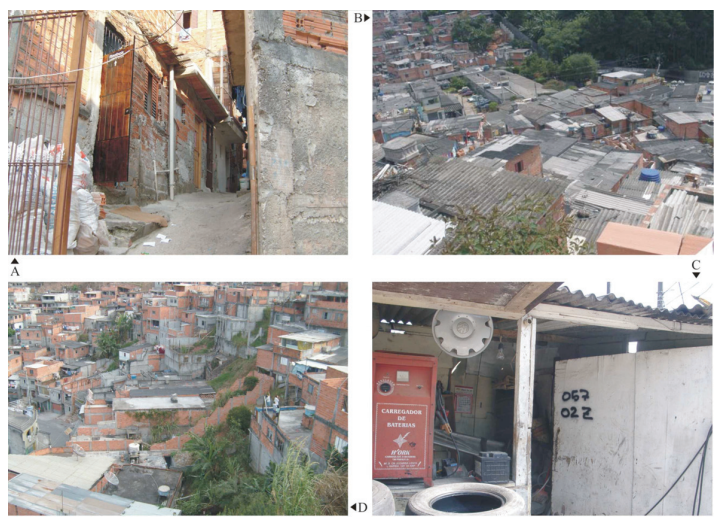

Fot. 1 - (A) precariedade do sistema viário; (B e C) alta densidade edificada; (D) exercício de actividades irregulares

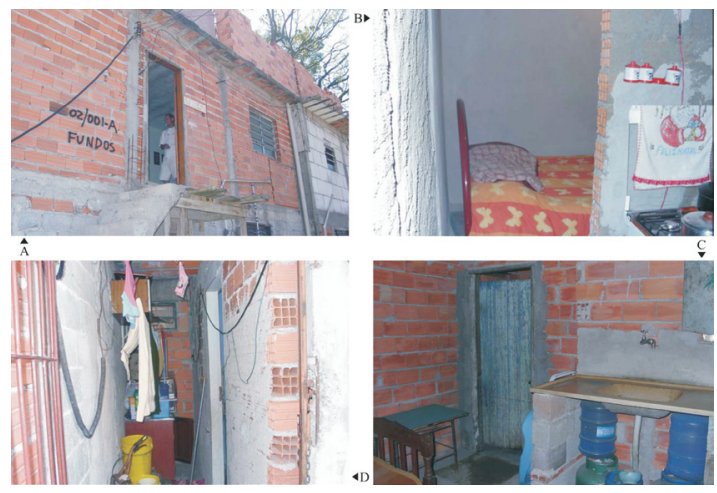

Fot. 2 - (A) autoconstrução; (B) baixa compartimentação interna; (C) instalação elétrica domiciliar precária;

(D) gás liquefeito de petróleo - GLP.
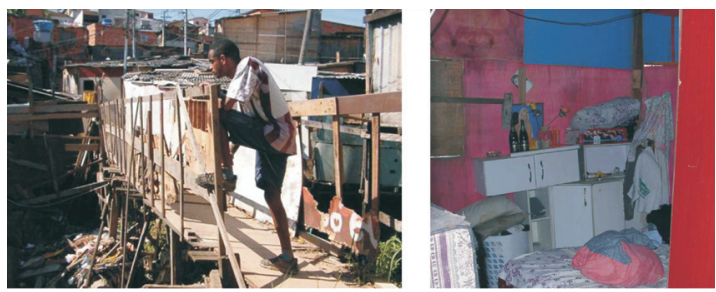

Fot. 3 - Situações de pobreza/ vulnerabilidade social. de acesso dos caminhões, e 32,9\% das vias internas aos assentamentos não são pavimentadas; exercício irregular de atividades comerciais: depósitos de gás, ferro-velho, bares, lanchonetes etc.

- características da unidade domiciliar, com impactos na ignição, em virtude da proximidade de fontes de calor a materiais combustíveis (em farta quantidade e acondicionados inadequadamente), no desenvolvimento dos incêndios e nas perdas (materiais e humanas) deles decorrentes (fot. 2): autoconstrução das moradias (por definição, as edificações são construídas sem assistência técnica profissional, determinando a ausência de segurança estrutural e de seus componentes, como instalações); exigüidade do espaço físico (30\% das moradias possuem até três cômodos, condição inferior ao parâmetro mínimo referente às quatro funções básicas do morar higiene, alimentação, repouso, estar - , determinando sua sobreposição e ausência de compartimentação interna, e 32,2\% dos domicílios são congestionados, ou seja, possuem mais de uma pessoa por cômodo);

- precariedade da infra-estrutura instalada e de serviços ofertados, com impactos na ignição do fogo e na proteção do exposto: abastecimento informal de energia elétrica $(38,8 \%$ dos domicílios não possuem medidor e 1,3\% dos domicílios não são abastecidos); rede de serviços sociais insuficiente $\mathbf{( 5 4 , 9 \%}$ das crianças de zero a 6 anos não freqüentam a pré-escola ou creche);

- características socioeconômicas da população moradora, ou alto nível de vulnerabilidade social (fot. 3), com impactos no acesso a serviços essenciais (energia elétrica - problema tarifário), a informações, e baixa possibilidade de investimento nos imóveis, entre outros, que, por sua vez, repercutem sob diversos aspectos na segurança contra incêndios: famílias numerosas ( $58 \%$ possuem quatro ou mais membros e $11,3 \%$ das famílias possuem quatro ou mais filhos na sua composição); famílias chefiadas por grupos vulneráveis (25,8\% dos chefes são mulheres, em decorrência de viuvez ou separação conjugal e $48,1 \%$ das famílias são chefiadas por jovens, até 24 anos, ou adultos jovens, 24 a 39 anos); baixa e baixíssima renda $(74,5 \%$ das famílias possuem renda de até 3 salários mínimos, US\$ 610 , sendo que $66,6 \%$ situam-se abaixo da linha de pobreza - satisfação de necessidades alimentares, de moradia, vestuário e higiene - 31,9\%, abaixo da linha de indigência; perfil populacional jovem (20,9\% da população possuem entre zero e 9 anos); baixa escolaridade $(64,9 \%$ dos chefes de família não completaram o ensino fundamental e $56,2 \%$ dos jovens entre 18 e 24 anos não concluíram o ensino médio).

Essas condicionantes encontram-se refletidas nas causas dos eventos ocorridos na cidade de São Paulo, 
entre os anos de 2001 e 2003, sendo a principal delas as instalações elétricas inadequadas, que respondeu por $40,91 \%$ dos eventos. Também é relevante, conforme se verá nos Quadros II e III adiante apresentados, a contribuição daquelas associadas, por interpretação, às características da unidade domiciliar, e à violência, aspecto não apontado, mas sabidamente presente nessas ocupações.

O agrupamento de causas relacionadas às condições das unidades domiciliares (QUADRO III), bem como as quatro categorias, a saber, ação humana intencional, ação humana não intencional, fenômeno natural e causas materiais, apresentadas no QUADRO II, foram propostos pela autora em função da diversidade de causas catalogadas pelo Corpo de Bombeiros da Polícia Militar do Estado de São Paulo (CBPMESP), e da necessidade de compreensão de seus significados de maneira abrangente, além de contribuir para as etapas decorrentes de análise de riscos e indicação de medidas de segurança pertinentes.

Pelo exposto, numa abordagem convencional, a partir de um sistema teórico que discrimine os elementos constitutivos da segurança contra incêndios, no qual a insegurança seja dada em relação à presença ou ausência desses componentes, a favela, enquanto categoria, estaria situada no patamar máximo do risco; sujeita, portanto, à ocorrência de desastres e catástrofes regulares. Entretanto, não é isso que se vê.

Para elucidar as razões da distância entre a fatalidade anunciada e a realidade de que a maior parte das favelas nunca sofreu incêndios severos, ao passo que se observam algumas como objeto de eventos repetidos, há que se compreender esta questão bastante simples: assim como um incêndio não é igual a outro, as favelas também não o são ${ }^{11}$.

QUADRo II - Causas prováveis agrupadas por categorias (2001/ 2003)

\begin{tabular}{|l|c|c|}
\hline $\begin{array}{c}\text { Causas relacionadas às condições } \\
\text { da unidade habitacional }\end{array}$ & $\begin{array}{c}\text { N. }^{\circ} \\
\text { absoluto }\end{array}$ & $\%$ \\
\hline Displicência ao cozinhar & 16 & $8,08 \%$ \\
\hline Negligência com vela & 13 & $6,57 \%$ \\
\hline Brincadeira de crianças & 8 & $4,04 \%$ \\
\hline Vazamento de GLP & 5 & $2,53 \%$ \\
\hline $\begin{array}{l}\text { Displicência de fumantes com } \\
\text { ponta de cigarro ou fósforos }\end{array}$ & 4 & $2,02 \%$ \\
\hline $\begin{array}{l}\text { Acender fósforo ou isqueiro em } \\
\text { local de risco }\end{array}$ & 3 & $1,52 \%$ \\
\hline $\begin{array}{l}\text { Acondicionamento de material } \\
\text { combustível em local de risco }\end{array}$ & 1 & $0,51 \%$ \\
\hline $\begin{array}{l}\text { Vazamento de combustível em } \\
\text { local aquecido }\end{array}$ & 1 & $0,51 \%$ \\
\hline $\begin{array}{l}\text { Total } \\
\text { and }\end{array}$ & 198 & $\mathbf{2 5 , 7 8 \%}$ \\
\hline
\end{tabular}

QUADRO III - Causas associadas às condições da unidade habitacional

\begin{tabular}{|c|c|c|}
\hline Categorias / Causas & N. ${ }^{\circ}$ absoluto & $\begin{array}{c}\text { Percentual } \\
\text { sobre } 0 \\
\text { total }\end{array}$ \\
\hline Causa material & 87 & $43,94 \%$ \\
\hline $\begin{array}{l}\text { Instalação elétrica inadequada (curto circuito, } \\
\text { sobrecarga) }\end{array}$ & 81 & $40,91 \%$ \\
\hline Vazamento de GLP & 5 & $2,52 \%$ \\
\hline Vazamento de combustível em local aquecido & 1 & $0,51 \%$ \\
\hline Ação humana intencional & 63 & $31,82 \%$ \\
\hline Ato incendiário & 57 & $28,79 \%$ \\
\hline Prática de ações criminosas & 6 & $3,03 \%$ \\
\hline Ação humana não intencional & 45 & $22,73 \%$ \\
\hline Displicência ao cozinhar & 16 & $8,08 \%$ \\
\hline Negligência com vela & 13 & $6,57 \%$ \\
\hline Brincadeira de crianças & 8 & $4,04 \%$ \\
\hline $\begin{array}{l}\text { Displicência de fumantes com ponta de cigarro } \\
\text { ou fósforos }\end{array}$ & 4 & $2,02 \%$ \\
\hline Acender fósforo ou isqueiro em local de risco & 3 & $1,52 \%$ \\
\hline $\begin{array}{l}\text { Acondicionamento de material combustível em } \\
\text { local de risco }\end{array}$ & 1 & $0,51 \%$ \\
\hline Fenômeno natural & 3 & $1,52 \%$ \\
\hline Igniçâo espontânea & 2 & $1,01 \%$ \\
\hline Raio & 1 & $0,51 \%$ \\
\hline Total & 198 & \\
\hline
\end{tabular}

As favelas possuem marcadamente a característica da irregularidade, do ponto de vista legal e urbanístico, e entre si apresentam larga heterogeneidade; também, é natural ao fenômeno do incêndio que seu comportamento seja moldado pela situação concreta em que ele se desenvolve, o que faz dos incêndios em favelas um problema extremamente complexo.

\section{Método de análise de risco de incêndios em favelas: uma abordagem}

A gestão do risco de incêndios em favelas deve ter como premissa que se está a falar de um conjunto de assentamentos semelhantes e dissemelhantes, condição responsável por uma diferenciação substantiva entre os níveis de risco presentes em cada um deles. As imagens adiante apresentadas (fot. 4) ilustram e justificam essa abordagem.

Além disso, a definição de estratégias para lidar com o problema deve também considerar o universo, no caso da cidade de São Paulo, de cerca de 1600 favelas $^{12}$, e 
a capacidade de atuação institucional limitada, pelo viés dos recursos humanos ou materiais, situações essas similares a outras capitais e cidades médias do país, o que faz da otimização um atributo da eficácia.

É evidente que seria ideal haver uma atuação sobre todos os assentamentos, de forma a minimizar o risco pertinente a cada um deles. Entretanto, é também evidente, em face do contexto colocado, que essa estratégia não é viável ou somente poderia resultar na

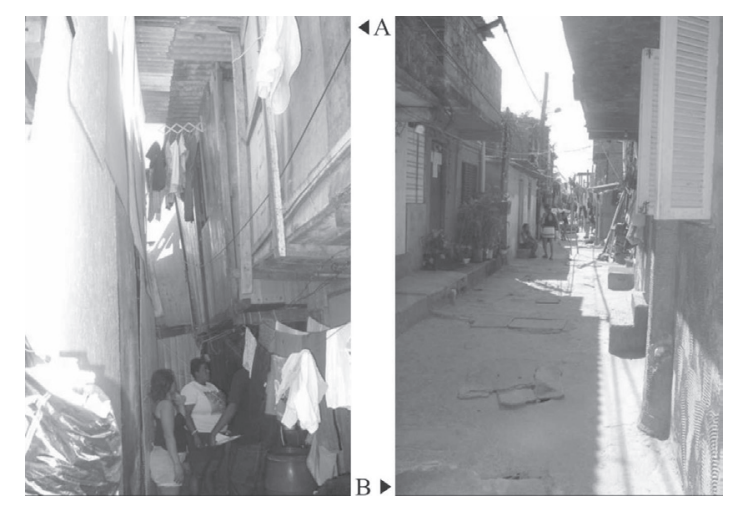

Fot. 4 - Heterogeneidade das favelas: (A) domicílios em madeira, construções próximas, condições precárias de acesso; (B) situação consolidada.

falta de focalização das ações. Daí decorre a necessidade de um instrumento para a análise de riscos, que deve estar alinhado com os objetivos de gestão pretendidos.

Esses objetivos podem ser concebidos em duas vertentes: uma que seja a atuação preventiva e emergencial sobre assentamentos com alto nível de risco, ou seja, com maior probabilidade de ocorrência de incêndios e maiores consequiências para a população envolvida, e outra, voltada à incorporação de medidas perenes de segurança nos assentamentos que venham a ser objeto de urbanização, ou seja, de intervenções estruturais de caráter global.

Admite-se nisso haver um conjunto de favelas que poderia conviver com o risco de incêndios, dado que este seria muito baixo, não justificando um esforço de atuação antecipada ao tratamento urbanístico do assentamento como um todo. A demarcação dessa linha divisória entre risco e segurança, dada pelo estudo dos eventos pregressos, é, na verdade, a mesma que demarca a concepção da forma da análise de riscos a ser empregada.

A abordagem em duas vertentes da gestão tem diversos rebatimentos, sendo o mais evidente a definição, a partir desses objetivos distintos, de uma dupla finalidade e de dois momentos de análise, aos quais devem corresponder dois métodos: um para apontar o grupo de assentamentos críticos, com vistas ao desenvolvimento de ações preventivas e emergenciais $^{13}$ (objetivo de priorizar), e outro para diagnosticar e sugerir a implantação de medidas perenes nos casos de intervenções de caráter global (objetivo de esgotar), podendo este ter um parâmetro, inclusive, bastante mais exigente com relação ao nível de segurança perseguido.

Esses dois tipos de análise, além de possuirem objetivos distintos, ou justamente por esse motivo, são operados em escalas - espaço e tempo - diferentes. Para o objetivo de priorizar, é necessário avaliar o conjunto das favelas, em períodos concentrados (pouco tempo destinado a todas); para o objetivo de esgotar, cada uma das favelas é avaliada individualmente, o que pode ocorrer em períodos diluídos pelo processo de intervenção, que perpassa seleção, desenvolvimento de projetos e execução de obras (muito tempo destinado a uma).

Paradoxalmente, a abrangência da primeira, em termos da quantidade de objetos a serem avaliados, determina que as variáveis consideradas na análise sejam mais restritas, ou seja, atenham-se às essenciais: aquelas que efetivamente determinam grandes probabilidades e graves conseqüências na ocorrência de um evento. Enquanto na primeira a gestão só se realiza a partir de uma análise que pressuponha generalizações, no caso a caso da segunda, complexidades na análise são admitidas, e inclusive desejáveis, para a tomada de decisões.

Ou seja, com o objetivo de focalizar, o método deve, por definição, ser simples e ágil; com o objetivo de aprofundar, pode ser minucioso e específico, composto de leituras associadas sobre o território, considerando os diversos fatores constitutivos do risco, configurando mais uma diretriz do que propriamente um método.

É simples perceber essas concepções quando se faz a relação com as causas diretas dos incêndios: para o objetivo de focalizar, não interessam as variáveis fixas, ou seja, aquelas que, presume-se e admitese, se manifestem de maneira homogênea entre os assentamentos, como as associadas às condições da unidade habitacional, ou as relacionadas a atos voluntários (ação humana intencional), ou ainda, à vulnerabilidade social da população.

Entretanto, fazem muita diferença: a eletrificação (ausência ou precariedade da rede instalada), as características urbanísticas dos assentamentos, como materiais construtivos (domicílios em madeira), densidade, sistema viário, além de outros aspectos, como localização na cidade, que se manifestem de maneira singular em cada núcleo. Também não se pode medir, ou considerar, o que não se pode observar, de forma que uma variável válida é aquela singular e mensurável.

O descarte de variáveis para o objetivo de um método de focalização do risco, no entanto, não as elimina do contexto de uma política global de segurança contra 
incêndio em favelas, porque esta vai muito além de uma atuação preventiva e emergencial no nível local, envolvendo mais de um setor e mais de uma esfera de governo.

As questões referentes à degradação do espaço da favela e de acesso à energia elétrica demandam ações estruturais, como a efetivação do acesso à habitação formal e da energia elétrica pela população de baixa renda, por exemplo, que estão ligadas a aspectos de renda, de consumo, de tarifação, somente para citar alguns.

\section{Conclusão}

Este artigo é fruto do estágio atual da pesquisa de doutorado em desenvolvimento pela autora no âmbito do Programa de Pós-Graduação da Faculdade de Arquitetura e Urbanismo da Universidade de São Paulo, que tem como desafio e objetivo principal a proposição de um modelo aplicável à análise de riscos de incêndios em favelas, a partir do universo dos assentamentos paulistanos e sua inserção no contexto institucional local.

A grande questão que se coloca neste trabalho, pelo próprio paradoxo do problema, que é a necessidade de controle para a segurança contra incêndios versus a espontaneidade - em regra - por meio da qual se constituem as favelas, é a constatação de que objetos heterodoxos não podem ser analisados e trabalhados sob uma perspectiva ortodoxa, ou, melhor dizendo, a partir de padrões exógenos a eles. A condição radical, da presença de múltiplas variáveis, de múltiplas combinações possíveis, em certa medida imprevisíveis, impõe limitações à aplicação de métodos analíticos pré-concebidos.

Trata-se, sobretudo, da tentativa de construir uma forma de olhar adequada, para uma nem tão adequada forma de morar, que, entretanto, vem se tornando de exceção à regra: "a maioria dos pobres urbanos do mundo não mora mais em bairros pobres no centro da cidade. Desde 1970 , o maior quinhão do crescimento populacional urbano mundial foi absorvido pelas comunidades faveladas da periferia das cidades do Terceiro Mundo" (Davis, 2006, p. 46).

\section{Notas}

1. Os primeiros registros de favelas na cidade de São Paulo datam dos anos 1940. Neste trabalho, utiliza-se como base a definição de favela atualmente adotada pela Prefeitura do Município de São Paulo: “favelas - todos os assentamentos precários de áreas públicas ou particulares de terceiros, cuja ocupação foi feita à margem da legislação urbanística e edilícia”, descritas, na referência conceitual, como "ocupações predominantemente desordenadas, com precariedade de infra-estrutura, com maior opção pela autoconstrução das moradias que apresentam diferentes graus de precariedade", sendo que "a população residente caracteriza-se por famílias de baixa renda e socialmente vulneráveis" (SEADE, 2008, p.2)

2. O dimensionamento da população e domicílios favelados não é tarefa simples, sobretudo quando a intenção é traçar um quadro evolutivo das favelas na cidade para os últimos trinta anos. Isso porque as fontes de dados disponíveis costumaram adotar conceitos, metodologias e periodicidade inconstantes. Assim, adotaremos sempre que possível os dados disponibilizados oficialmente pela Prefeitura do Município de São Paulo (PMSP) ou consagrados pela literatura especializada, como os de TASCHNER (1997) para a década de 1970.

3. Regularização fundiária plena é o conjunto de medidas sociais, urbanísticas, jurídicas e ambientais que têm como objetivo a integração de assentamentos irregulares ao contexto urbano formal, incluindo o acesso a bens e serviços públicos.

4. No Município de São Paulo, o programa, entendido como um conjunto de ações sistemáticas e coordenadas, foi iniciado na gestão 2001-2004, e se encontra institucionalizado, com mapeamento das áreas de risco e planejamento de intervenções conforme uma hierarquia de prioridades com base nele definida.

5. Na literatura especializada sobre a problemática habitacional urbana e as favelas, os incêndios (ou o seu risco) são apontados como mais um fator denotativo da precariedade das condições de moradia, sem alçar à condição de protagonista; na mesma linha, a produção sobre a ciência do fogo e o fenômeno dos incêndios ainda não alcançou o campo do espaço urbano informal.

6. Vide notas 2 e 7 .

7. Os dados relativos às ocorrências de incêndios citados neste artigo referem-se sempre ao Município de São Paulo, possuindo como base os dados primários fornecidos pelo Corpo de Bombeiros da Polícia Militar do Estado de São Paulo (CBPMESP), manipulados pela autora. As informações disponibilizadas abarcam o período de janeiro de 1993, ano em que o CBPMESP passou a adotar um novo modelo de coleta, a outubro de 2003 , em dados resumidos (registro das ocorrências), e dados abertos (completos, incluindo causas e circunstâncias dos eventos) para os anos de 2001, 2002 e 2003, de acordo com o recorte estabelecido por esta pesquisa. Foram utilizadas duas categorias de dados, a saber, "barraco" e "favela", sendo o primeiro assumido, quando conveniente (para a ampliação da amostra na análise de causas), como um incêndio em favela que não se generalizou. Com base nisso é que foi construído o gráfico apresentado na figura 1.

\section{Vide nota 6.}

9. Todos os dados apresentados, com exceção dos índices de densidade, produzidos pela autora a partir da mesma fonte, combinada a dados de área ocupada por favelas disponíveis em www. habisp.inf.br, foram obtidos em SEADE (2008).

10. Todas as fotografias apresentadas neste trabalho foram obtidas pelo arquiteto José Eduardo Rossato de Campos, no período de 2005 a 2008, em diversas favelas da cidade de São 
Paulo. Como não estamos tratando de casos específicos, mas sim de tipos, não fazemos menção à favela e à data da imagem, porque não consideramos ser esta uma informação relevante para a compreensão dos conteúdos discutidos.

11. São condicionantes para a constituição das favelas: o sítio (encostas, vales, espaços residuais da cidade, vãos sob pontes e viadutos etc.), a forma de ocupação original (organizada ou espontânea, repentina ou gradual), o tempo de existência (a tendência geral é a consolidação das favelas, com gradativa substituição do material provisório original), as características sociais, econômicas e culturais da população moradora (acesso a meios e técnicas construtivas, nível de conscientização, capacidade de investimento individual e coletivo etc.) e o seu nível de organização e representatividade política (pleito junto a órgãos oficiais, conquistas comunitárias etc.), associadas num movimento marcadamente dinâmico.

12. Dados oficiais da Prefeitura do Município de São Paulo; http://www.habisp.inf.br/aspnet/aspx/espacohabitado/ favelalista.aspx [18/06/09];

13. O CBPMESP já prevê, para casos que fogem aos padrões definidos em norma, como as favelas, tratamento diferenciado, através da elaboração dos PPI's - Plano Particular de Intervenção. Esses planos constituem-se em análises de cada situação específica, realizadas através de levantamentos de campo, em locais previamente definidos, pelas equipes dos Postos de Bombeiros (que constituem a "ponta" do atendimento) na sua região de abrangência. Entretanto, a quantidade de favelas no Município de São Paulo reduz a eficácia do instrumento pela dificuldade de elaboração.

\section{Referências bibliográficas}

DAvIs, Mike (2006) - Planeta Favela. São Paulo, Boitempo Editorial, $272 \mathrm{p}$.

BERTO, Antonio Fernando (1991) - Medidas de proteção contra incêndio: aspectos fundamentais a serem considerados no projeto arquitetônico dos edifícios. São Paulo, Universidade de São Paulo - Faculdade de Arquitetura e Urbanismo (FAU-USP).

Maricato, Ermínia (2000) - As idéias fora do lugar e o lugar fora das idéias - Planejamento urbano no Brasil. In: Arantes, Otília; Vainer, Carlos E Maricato, Ermínia - A cidade do pensamento único: desmanchando consensos. Petrópolis, Vozes, 192 p., p.121-192.

Mitidieri, Marcelo Luis (2001) - Submoradias Localizadas sob os Vãos de Pontes e Viadutos da Cidade de São Paulo: os incêndios, suas causas $e$ conseqüências (Artigo cedido pelo autor, São Paulo).
Ono, Rosária (1997) - Segurança contra Incêndio em Edificações - um sistema de coleta e análise de dados para avaliação de desempenho. São Paulo, Universidade de São Paulo - Faculdade de Arquitetura e Urbanismo (FAU-USP).

ReIS Filho, Nestor Goulart (1996) - Urbanização e Planejamento no Brasil - 1960-1983. São Paulo, Universidade de São Paulo - Faculdade de Arquitetura e Urbanismo (FAU-USP), Cadernos de Pesquisa do LAP (série Urbanização e Urbanismo), $62 \mathrm{p}$.

Rosso, Teodoro (1975) - Incêndios e Arquitetura. São Paulo, Universidade de São Paulo - Faculdade de Arquitetura e Urbanismo (FAU-USP).

SEITo, Alexandre Itiu (1995) - Metodologia de Análise de Risco de Incêndio. Dissertação de Mestrado. São Paulo, Universidade de São Paulo, Faculdade de Arquitetura e Urbanismo.

TASCHNER, Suzana Pasternak (1997) - Política Habitacional no Brasil: Retrospectivas e Perspectivas. São Paulo, Universidade de São Paulo - Faculdade de Arquitetura e Urbanismo (FAU-USP), Cadernos de Pesquisa do LAP (série Habitação Popular), 73 p.

Sítios na Internet , (2001) - Favelas em São Paulo - censos, consensos e contra-sensos: http:// bibliotecavirtual.clacso.org.ar/ar/libros/ anpocs00/gt07/00gt0723.doc; [18/06/2009].

CbPMesp (Corpo de Bombeiros da Polícia Militar do Estado de São PAulo) Instrução Técnica no 16/01 - Plano de Intervenção de Incêndio:

http: //www.polmil.sp.gov.br/ccb/. [13/11/2003].

SEAdE (Fundação Sistema Estadual de Análise de Dados) (2008) - Atualização de dados censitários de favelas e loteamentos irregulares do município de São Paulo, Relatório Analítico, maio de 2008: www.habisp.inf.br. [13/05/09];

Torres, Haroldo, MARques, Eduardo e Saraiva, Camila (2003) Favelas no Município de São Paulo: estimativas de população para os anos de 1991, 1996 e 2000, Artigo produzido para apresentação no $X$ Encontro Nacional da Associação Nacional de Planejamento Urbano e Regional (X ENANPUR) realizado em Belo Horizonte em maio de 2003: http://www.centrodametropole.org.br/ textos.html.[18/06/09] 